\title{
Association between Creativity and COMT genotype
}

\author{
Liping Lu \\ the Institute of Psychology, Chinese Academy of Science \\ CAS \\ Beijing, China \\ lulp@psych.ac.cn
}

\author{
Jiannong Shi \\ the Institute of Psychology, Chinese Academy of Science \\ CAS \\ Beijing, China \\ shijn@psych.ac.cn
}

\begin{abstract}
Catechol-O-methyl transferase (COMT) influences dopamine concentration in the pre-frontal cortex (PFC). The G/A transition in the exon 4 of the COMT gene, which results in a valine (Val) to methionine (Met) amino acid substitution (Val158Met), can bring on different enzymatic activities. Much research has found that the Met/Met genotype associated with low enzymatic activity and may enhance cognitive function. Our research aimed to test the association between COMT genotype and creativity. We applied one-way ANOVA to detect the effect of the COMT genotypes to creative ability and creative potentials in 108 Chinese children with polymerase chain reaction (PCR) methods. COMT genotypes were not related to creative ability and creative potential except imagination. Val/Val carriers are more likely to imagine than Met/Met carriers $\left(F_{(2,105)}=4.082\right.$, $p=.02)$. We also found that COMT Val158Met polymorphism had a significant main effect on intelligence $\left(F_{(2,102)}=3.47, p=0.035\right)$ and it could predict $4.7 \%$ of intelligence. Our results suggest that Met/Met genotype has a positive effect on intelligence but not on creative ability. However, we found no significant interaction between gender and COMT genotype to intelligence.
\end{abstract}

Keywords- creative ability; creative potential; Catechol-Omethyl transferase (COMT); functional polymorphism

\section{INTRODUCTION}

Intelligence, which is a highly heritable behavior phenotype [1], is one of the most frequently investigated constructs for its high prediction of academic achievement and success in daily life [2]. However, creativity research, which has "the role of a prodigal stepbrother to intelligence research" [3], is rather orphaned especially for its heredity research [4].

Creativity is the ability to produce something that is novel and useful $[3,5,6]$. Although it is an important psychological construct not only to solve problems in work and daily life but also to improve and advance human society, creativity is often neglected by many researchers for inconsistent understandings of creativity. Some researchers consider creativity as the product that only very few individuals manage to own, while others investigate creativity through the process approach and assume that creativity is normally distributed in the general population just like intelligence [7]. Supporters of the process approach like Guilford [8] took originality, flexibility and elaboration as the core of creativity and tried to develop appropriate instruments to measure it. As most scientists supported the process approach at present, we took this scientific standpoint as our theoretical footstone.

Creativity and divergent thinking are incorporated into intelligence in some intelligence models $[9,10,11]$. And as the process approach assumed, creativity is normally distributed in the population which is also similar as intelligence. Therefore, creativity should also have a strong genetic basis as intelligence. However, there were little researches about the genetic basis of creativity and its heritability until now.

Most scientists supported that creativity is the results of many factors $[12,13,14]$. Many researchers emphasized that some personality traits can improve creative ability $[5,15,16]$. Sternberg (1985) reviewed the concept of the persons who owned high creative ability from experts to laymen and found that the implicit concept of creativity tried to take creative ability and some personality traits such as novelty seeking and imagination as a whole [17]. So in this paper, we assess creativity from two parts: creative ability and creative behavior which is also called as creative potential. Creative potential is an interesting behavior trait for creativity research not only for its biological basis [18] but also because it is an important feeling behavior necessary for the efficient production of creative thought. In our research, we departed creative potential into four parts: curiosity, imagination, novelty seeking and challenge as Williams (1972) [19], which has been accepted by many experts on creativity.

COMT gene is a genetic marker documented to impact cognitive functioning, which is coded by catechol-Omethyltransferase (COMT) enzyme. This enzyme is a major enzymatic inactivator of the neurotransmitter dopamine and regulates the duration of dopamine effect by catabolizing more than $60 \%$ of the dopamine in the prefrontal lobe $[20,21]$. Prefrontal cortex was the central system of human cognitive activities and was directly associated with human intelligence [22]. Functional variation in the human COMT gene occurs at a single nucleotide polymorphism (SNP), which is a $G \rightarrow A$ transition coding for the synthesis of the amino acid methionine (Met) instead of valine (Val) in codon 158 of the COMT gene located at the q11 band of human chromosome 22 (GenBank accession no. AY341246), bringing on 3- to 4-fold difference in COMT enzyme activity [23]. The Val allele associates with high enzymatic activity while the Met allele associates with low. In addition, dopaminergic

National Natural Science Foundation of China (No: 30670716) 
neurotransmission in the PFC contributes to individual cognitive differences [24], thus COMT genotype may influence cognitive performance, especially intelligence.

Many researches support the association between COMT genotypes and the performance of the prefrontal lobe in children $[25,26]$. With these data, individuals with the low activity Met allele are hypothesized to perform better on cognition tests that are specific for PFC functions [27]. Consistent with the hypothesis, Egan et al (2001) observed that the Met allele was related to the better performance on the Wisconsin Card Sorting Test (WCST), which was replicated by Malhotra et al. (2002) [28]. Another research reported that individuals with Met allele performed better in the processing speed and attention domain [29]. Consistent with these findings, Goldberg et al. (2003) also found the Met/Met genotype carriers perform best in working memory while $\mathrm{Val} / \mathrm{Val}$ genotype carriers perform worst in an n-back task [30]. Another research support a general effect of COMT Val158Met polymorphism on cognition with biophysical data: P300 latency was lower in young Chinese women with the Met/Met genotypes [31]. Ho et al. (2005) found prefrontal cortical inefficiency in schizophrenic Val carriers with positron emission tomography (PET), which confirmed the relationship between COMT genotype and cognition [32]. Zhang et al. ( 2006) found no association between COMT genotypes and mental retardation (MR) but an association between COMT genotype and general cognitive ability of Chinese healthy children in mountain areas [33]. Recent study also found that the Met/Met carriers had better scores on executive function tests than Val-carriers [34]. Therefore, the aim of this paper was to find whether COMT genotype is a candidate gene for both creative ability and creative behavior potential.

\section{METHODS}

A total of 108 healthy unrelated Chinese children volunteers were randomly recruited from a compulsory educational school in Peking. Both these children and their parents agreed to participate in this research and provided written informed consent after explanation of the study. Two children excluded for missing data in the creativity test. Participants in our study were ranging from 6 years old to 14 years old with mean age of 10.36 and S. D. of 3.09. There were 51 boys and 57 girls and there was no association between gender and grade $\left(\mathrm{F}_{(1,106)}=2.35, p=.13\right)$.

All children participants were administered the following creative tests: Williams creative potential test to measure their creative behavior and the figural manuscript of Torrance tests of creative thinking (TTCT) to test their creative ability [35]. Thinking creatively with pictures can reflex children's creative ability without any interference of their knowledge. It measures creative thinking using three picture- based exercises to assess five mental characteristics: fluency, originality, elaboration, abstractness of titles, and resistance to closure. The TTCTFigural was proved with reasonable reliability [36].

Children were also tested IQ with the culture fair test (CFT). As intelligence and creativity are highly correlated, it is necessary to exclude the possibility that intelligence may play a modulatory role on the association between creativity and genotypes [37]. As CFT is widely spread and can avoid culture bias, we can conduct this test to compare the IQ scores with children in other nations in our future study. Furthermore, CFT examines fluid intelligence containing concept formation and reasoning ability, which is the core of intelligence and basal cognitive abilities [38]. Given the age differences, we computed $\mathrm{Z}$ scores for the calculation of CFT raw scores. Then we used $\mathrm{T}$ score which is calculated by $50+10 * \mathrm{Z}$ as the IQ index to make the data more descriptive.

In order to extract children's DNA, $2 \mathrm{ml}$ peripheral blood leukocytes were phlebotomized with the standard alcoholtrichlomethane method. The samples were immediately transported to the genetic lab and stored at $-20^{\circ} \mathrm{C}$. The primers used to amplify the target $217 \mathrm{bp}$ COMT gene fragment were identical to previous reports (Ruth et al. 2006). The upstream sense primer was 5'-TCG TGG ACG CCG TGA TTC AGG-3' and the downstream reverse primer was 5'-AGG TCT GAC AAC GGG TCA GGC-3'. PCR reactions were carried out in a final volume of $15 \mu \mathrm{l}$ consisting of $50 \mathrm{ng}$ of genomic DNA, $0.4 \mu \mathrm{l}$ of each primers $(10 \mathrm{pM}), 10 *$ PCR Buffer, $0.2 \mu \mathrm{l}$ of $500 \mathrm{U}$ Taq, $0.2 \mu \mathrm{l}$ of $10 \mathrm{mM}$ dNTP, $1.0 \mu \mathrm{l}$ of $25 \mathrm{mM} \mathrm{MgCl}_{2}$ and $10 \%$ DMSO. We found the best PCR conditions for our experiment to be touchdown protocol. It began with an initial denaturation step at $95 \circ \mathrm{C}$ for $3 \mathrm{~min}$, followed by 20 cycles of denaturation at $94{ }^{\circ} \mathrm{C}$ for $1 \mathrm{~min}$, annealing at $68^{\circ} \mathrm{C}$ for $30 \mathrm{~s}$ in the first cycle and lowering the annealing temperature sequentially from $68{ }^{\circ} \mathrm{C}$ to $58{ }^{\circ} \mathrm{C}$ over these 20 cycles, and extension at $72{ }^{\circ} \mathrm{C}$ for $45 \mathrm{~s}$. There were 20 additional cycles for further amplification annealing at $58^{\circ} \mathrm{C}$ for $30 \mathrm{~s}$ per cycle. In the end, the samples were extended at $72 \circ \mathrm{C}$ for $10 \mathrm{~min}$. The PCR products were digested at $37{ }^{\circ} \mathrm{C}$ for $3 \mathrm{~h}$ with $5 \mathrm{U}$ of the restriction enzyme NIa III (New England Biolabs). Products were electrophoresed on a $4 \%$ agrose gel. A DL500 Marker was used to measure the fragments size.

\section{RESULTS}

The $\mathrm{H}$ allele, high activity Val-108, was cleaved into 2 bands: the $136 \mathrm{bp}$ band and the $81 \mathrm{bp}$ band. The $\mathrm{L}$ allele, low activity Met-108, was cleaved into 3 bands in theory, the 114 bp band, the $81 \mathrm{bp}$ band and the $22 \mathrm{bp}$ band. However, the shortest band (22bp) cound not be shown on the gel. The COMT genotype distribution in our experiment for the 108 subjects was: $\mathrm{Val} / \mathrm{Val}=26, \mathrm{Val} / \mathrm{Met}=65$, Met $/ \mathrm{Met}=17$. Allele frequencies did not differ significantly from Hardy-Weinberg equilibrium (Chi-square $=5.41, \mathrm{df}=2, \mathrm{p}=.067$ ). We conducted a one-way ANOVA to compare cognitive performance across the three allele groups (Val/Val, Val/Met and Met/Met).

Total creativity and originality were significantly correlated with intelligence $(\mathrm{rc}=0.24, \mathrm{ro}=0.20)$. However, fluency and flexibility were not significantly related to intelligence (correlations ranging from 0.10 to 0.14 ). Results of the genetic analysis showed that there were no significant association between COMT genotype and all measures of creative test except imagination $\left(\mathrm{F}_{(2,102)}=4.08, p=0.020\right)$. We found significant main effects of the COMT genotypes on intelligence measures $\left(\mathrm{F}_{(2,102)}=3.47, p=0.035\right)$. COMT genotypes explained $4.4 \%$ of the interindividual variance with intelligence scores. Post hoc tests for univariate effects 
revealed that Met/Met carriers performed better than both $\mathrm{Val} / \mathrm{Val}$ and $\mathrm{Val} / \mathrm{Met}$ carriers $(p=.012, p=.028$ respectively). There was no significant difference between $\mathrm{Val} / \mathrm{Val}$ and Val/Met genotypes on their CFT scores. However, using the more conservative Bonferroni correction, we found that the only significant difference was between the $\mathrm{Val} / \mathrm{Val}$ and Met/Met genotypes $(p=.037)$. The Cohen's $d=-0.74$ and effect size is 0.346, which means middle effect. No significant interaction of gender and COMT genotypes on both the intelligence test and creative tests was found $\left(\mathrm{F}_{(2,105)}=1.621\right.$, $p=.203$ ).

TABLE I. the demographic and test information by COMT genotype

\begin{tabular}{lccc}
\hline & Val/Val $(\mathbf{n}=\mathbf{2 6})$ & Val/Met $(\mathbf{n}=\mathbf{6 5})$ & $\begin{array}{c}\text { Met/Met } \\
(\mathbf{n}=\mathbf{1 7})\end{array}$ \\
\hline Age & $9.9(3.1)$ & $10.8(3.0)$ & $10.4(3.1)$ \\
Gender (M/F) & $14 / 12$ & $28 / 37$ & $9 / 8$ \\
CFT test & $47.0(9.7)$ & $48.8(9.8)$ & $54.4(6.8) *$ \\
Total creativity & $50.0(6.8)$ & $50.47(6.04)$ & $49.5(4.6)$ \\
Originality & $49.1(10.1)$ & $52.0(8.7)$ & $49.3(6.6)$ \\
Fluency & $49.5(10.8)$ & $50.0(8.2)$ & $49.9(9.0)$ \\
Flexibility & $50.0(8.8)$ & $50.7(11.1)$ & $47.3(10.0)$ \\
Novelty seeking & $18.8(3.7)$ & $18.7(2.9)$ & $18.4(3.6)$ \\
Curiosity & $24.7(4.0)$ & $24.1(4.3)$ & $22.5(4.7)$ \\
Imagination & $25.5(5.2)$ & $23.1(4.7)$ & $21.6(3.2) *$ \\
Challenge & $21.8(3.5)$ & $21.5(3.5)$ & $20.1(3.5)$ \\
\hline Mean \pm S.D. Significantly different compared with Val/Val $\left({ }^{*} \mathbf{P}<0.05\right)$. &
\end{tabular}

\section{DISCUSSION}

Our study aimed to test the possible association between COMT genotype and creativity. Although there were many genetic studies concerning the cognitive function [24, 39], there was only one report on exploring the molecular basis of creativity for its difficulty to define and measure. Our study attempted to consider creative behavior and creative ability as a whole and measured them with the well-validated tests in creativity field. We found our results were different from the previous report [4]. We found there were no significant association between COMT genotype and creative ability, which is the same as previous report. But we found COMT genotype was significantly related to creative behavior, especially imagination $(\mathrm{F}=4.082, p=.020)$. With this result, we hypothesized that creative ability was apart from creative behavior in creative system. It meant that subjects who behaved highly creative may not be persons with high creativity. In order to prove our hypothesis, we tested the correlation between creative behaviors and creative ability and found no significant correlation between them (ranging from 0.03 to 0.13 ).

There were some researches about the association between COMT genotype and some personalities, such as harm avoidance, persistence $[18,40]$. However, no researches report on the association between COMT and creative personalities. The lack of this kind of researches is not for its importance but for the difficulty to give the exact definition of creativity. In our study, COMT gene is significantly associated with imagination and $\mathrm{Val} / \mathrm{Val}$ carriers performed much better in imagination test than the Met/Met carriers. The results of our study seemed strange: Met/Met carriers performed better than $\mathrm{Val} / \mathrm{Val}$ carriers in IQ test while $\mathrm{Val} / \mathrm{Val}$ carriers were more likely to imagine than Met/Met carriers. The possible explanation is that people with high IQ may not like to imagine in born than people with low IQ, although their creative ability don't differ from each other significantly. Our future research will validate this hypothesis to see whether it is true from behavior aspect.

In our study, we found COMT genotype was significantly related to intelligence, which was proved by many other studies but there were no association between COMT genotype and creative ability [24, 28, 30]. Although we haven't found the association between creative ability and COMT genotype, it didn't mean that creativity is not hereditary. The insignificance may be caused by the fact that COMT genotype was related to cognitive ability, but not related to creativity. So it is possible for us to draw the conclusion that the COMT gene is restricted to basal cognitive abilities but unrelated to higher cognitive ability such as creative ability.

\section{ACKNOWLEDGMENT (HEADING 5)}

We wish to thank all the participants and researchers who participated in this study. Our research was supported by the National Natural Science Foundation of China (No: 30670716).

\section{REFERENCES}

[1] L. Liping and S. Jiannong, "Association between intelligence and COMT genotype," unpublished.

[2] R. Plomin and L. A. Thompson, "Genetics and high cognitive ability," Ciba Found. Symp. 178, 1993, pp. 67-79.

[3] R. J. Sternberg, (Ed.), The nature of creativity: Contemporary psychological perspectives. Cambridge University Press, 1988.

[4] M. Reuter, S. Roth, K. Holve, \& J. Hennig, "Identification of first candidate genes for creativity: A pilot study," Brain research, vol 1069, 2006, pp.190-197.

[5] T. I.Lubart, "Product-centered self-evaluation and the creative process". Unpublished doctoral dissertation, Yale University, New Haven, CT. 1994.

[6] R. J. Sternberg and T. I. Lubart, "Investing in creativity". American Psychologist, vol. 51, 1996, pp. 677-688.

[7] A. Stavridou and A. Furnham, "The relationship between psychoticism, trait creativity and the attentional mechanism of cognitive inhibition," Personality and Individual Difference, vol. 21, 1996, pp. 143-153.

[8] J. P. Guilford, The structure of intellect. Psychology Bulletin, vol. 53, 1956, pp. 267-293.

[9] J. P. Guilford, The Nature of Human Intelligence. MacGraw-Hill, New York, 1967.

[10] J. P. Guilford, "Some incubated thoughts on incubation," Journal of Creative Behavior, vol. 13, 1979, pp. 1-8.

[11] A. O. Jäger, Berliner Intelligenzstruktur-Test (BIS-Test). Hogrefe, Göttingen, 1982.

[12] H. Gardner, Creating minds. New York: Basic, 1993.

[13] R.W. Weisberg, Creativity: Beyond the myth of genius. New York: Freeman, 1993.

[14] R. J. Sternberg, Successful intelligence. New York: Simon \& Schuster, 1996.

[15] R. J. Sternberg and T. I.Lubart, "An investment theory of creativity and its development, " Human Development, vol. 34, 1991, pp. 1-32

[16] R. J. Sternberg and T. I.Lubart, Defying the crowd: Cultivating creativity in a culture of conformaity. New York: Free Press, 1995. 
[17] R. J. Sternberg, "Implicit theories of intelligence, creativity and wisdom," Journal of Personality and Social Psychology, vol. 49, 1985, pp. 602-627.

[18] J. Benjamin, Y. Osher, P. Lichtenberg, R. Bachner-Melman, I Gritsenko, M. Kotler, R.H. Belmaker, V. Valsky, M. Drendel, R.P. Ebstein, "An interaction between the catechol-O-methyltransferase and serotonin transporter promoter region polymorphisms contributes to tridimensional personality questionnaire persistence scores in normal subjects, "Neuropsychobiology, vol. 41, 2000, pp. 48-53.

[19] Williams, "A total creativity program individualizing and humanizing the learning process," Educational Technology Publications, New Jersey, 1972.

[20] F. Karoum, S. J. Chrapusta and M. F. Egan, "3-Methoxytyramine is the major metabolite of released dopamine in the rat frontal cortex: reassessment of the effects of antipsychotics on the dynamics of dopamine release and metabolism in the frontal cortex, nucleus accumbens, and striaturn by a simple two pool model," Journal of Neurochemistry, vol. 63, 1994, pp. 972-979.

[21] M. Huotari, J. A. Gogos, M. Karayiorgou, O. Koponen, M. Forsberg, A. Raasmaja, J. Hyttinen, P. T. Mannisto, "Brain catecholamine metabolism in catechol-0-methyltransferase (COMT) deficient mice," European Journal of Neuroscience, vol. 15, 2002, pp. 2246-2256.

[22] R. J. Sternberg, "The holy grad of general intelligence," Science, vol. 289, 2000, pp. 399-401.

[23] H.M.Lachman,D.F.Papolos,T.Saito,Y.M.,Yu,C.L. Szumlanski, R.M.,Weinshilboum, "Human catechol-O-methyltransferase pharmacogenetics: description of a functional polymorphism and its potential application to neuropsychiatric disorders," Pharmacogenetics, vol. 6, 1996, pp. 243-250.

[24] M. F. Egan, T. E. Goldberg, B. S. Kolachana, J. H. Callicott, C. M. Mazzanti, R. E. Straub, D. Goldman, D. R. Weinberger, "Effect of COMT Val108/158 Met genotype on frontal lobe function and risk for schizophrenia," Proc. Natl. Acad. Sci. U.S.A., vol. 98, 2001, pp. 6917 6922.

[25] C. E. Bearden, A. F. Jawad, D. R. Lynch, S. Sokol, S. J. Kanes, D. M. McDonald-McGinn, S. C. Saitta, S. E. Harris, E. Moss, P. P.Wang, E. Zackai, B. S. Emanuel, and T. J. Simon, "Effects of a functional COMT polymorphism of prefrontal cognitive function in patients with $22 \mathrm{q} 11.2$ deletion syndrome," American Journal of Psychiatry, vol.161, 2004, pp.1700- 1702 .

[26] A. Diamond, L. Briand, J. Fossella, and L. Gehlbach, "Genetic and neurochemical modulation of prefrontal cognitive functions in children," American Journal of Psychiatry, vol. 161, 2004, pp. 125-132.

[27] I. J. Deary, L. J. Whalley, H. Lemmon, J. R. Crawford, J. M. Starr, "The stability of individual differences in mental ability from childhood to old age: follow-up of the 1932 Scottish Mental Survey," Intelligence, vol. 28, 2000, pp. 49-55.

[28] A. K. Malhotra, L. J. Kestler, C. Mazzanti, J. A. Bates, T. Goldberg, D. Goldman, "A functional polymorphism in the COMT gene and performance on a test of prefrontal cognition," American Journal of Psychiatry, vol. 59, 2002, pp. 652-654.

[29] R. M. Bilder, J. Volavka, P. Czobor, A. K. Malhotra, J. L. Kennedy, N. Xingqun, R. S. Goldman, M. J. Hoptman, B. Sheitman, J. P. Lindenmayer, L. Citrome, J. P. McEvoy, M. Kunz, M. Chakos, T. B. Cooper and J. A. Lieberman, "Neurocognitive correlates of the COMT Val158Met polymorphism in chronic schizophrenia," Society of Biological Psychiatry, vol. 52, 2002, pp. 701-707.

[30] T. E. Goldberg, M. F. Egan, T. Gscheidle, R. Coppola, T. Weickert, B. S. Kolachana, D. Goldman, D. R. Weinberger, "Executive subprocesses in working memory: relationship to catechol-O-methyltransferase Val158Met genotype and schizophrenia," Arch. Gen. Psychiatry, vol. 60, 2003, pp. 889-896.

[31] S. J. Tsai, Y. W. Yu, T. J. Chen, J. Y. Chen, Y. J. Liou, M. C. Chen, C. J. Hong, "Association study of a functional catechol-Omethyltransferase-gene polymorphism and cognitive function in healthy females," Neuroscience Letter, vol. 338, 2003, pp. 123-126.

[32] B. C. Ho, T. H. Wassink, D. S. O'Leary, V. C. Sheffield, N. C. Andreasen, "Catechol-O-methyl transferase Val158Met gene polymorphism in schizophrenia: working memory, frontal lobe MRI morphology and frontal cerebral blood flow," Molecular Psychiatry, vol. 10, 2005, pp. 287-298.

[33] K. J. Zhang, X. C. Gao, R. L. Li, C. Chao, S. P. Huang, F. C. Zhang, "Association between a functional COMT polymorphism, mental retardation and cognition in Qinba area children," Acta Genetica Sinica, vol. 33, 2006, pp. 495-500.

[34] J. M. Starr, H. Fox, S. E. Harris, I. J. Deary, L. J. Whalley, "COMT genotype and cognitive ability: A longitudinal aging study," Neuroscience Letter, vol. 421, 2007, pp. 57-61.

[35] E. P. Torrance, Torrance Tests of Creative Thinking. Lexington, MA: Personnel Press, 1974.

[36] D. J. Treffinger, Student Invention Evaluation Kit: Field test edition. Sarasota, FL: Center for Creative Learning, 1989.

[37] A. J. Cropley, "Creativity and intelligence." British Journal of Educational Psychology, vol.36, 1966, pp.259-266.

[38] R. Martin, R. Sarah, K. Holve, J. Hennig, 'Identification of first candidate genes for creativity: A pilot study.” Brain research, vol.1069, 2006, pp.190-197.

[39] R. Plomin, L. Hill, I. W. Craig, P. McGuffin, S. Purcell, P. Sham, D. Lubinski, L. A. Thompson, P. J. Fisher, D. Turic, M. J. Owen, "A genome-wide scan of 1842 DNA markers for allelic associations with general cognitive ability: a five-stage design using DNA pooling and extreme selected groups." Behavior Genetics, vol.31, 2001, pp. 497509.

[40] R. Hashimoto, H. Noguchi, H. Hori, et al., "A possible association between the Val158Met polymorphism of the COMT transferase gene and the personality trait of harm avoidance in Japanese healthy subjects." Neuroscience Letters, vol.428, 2007, pp.17-20. 